\title{
Program Sistem Manajemen Laboratorium Kimia Menggunakan Microsoft Visual Studio Community 2019 Berbasis Pengembangan Berkelanjutan
}

\author{
Budiman Prasetyo $^{1}$, Suwahono ${ }^{2}$, Ervin Tri Suryandari ${ }^{3}$ \\ 1,2,3Universitas Islam Negeri Walisongo \\ E-mail: 1 budimanprasetyo123@gmail.com, ${ }^{2}$ suwahono@walisongo.ac.id, \\ 3.dervin ts@walisongo.ac.id
}

\begin{abstract}
This research aims to develop tools in the form of a program (software) for desktops with a development model that is the Unified Process (UP). This development uses the help of the Microsoft Visual Studio Enterprise 2019 (Visual Basic.Net) program with the MySQL Workbench 8.0 CE database. After the program is built, the program is tested using the unit testing, integration testing, validation testing (alpha and beta testing) and system testing. Based on the results of testing this program is considered very feasible. The unit testing and integration testing achieved a success rate of $100 \%$. The results of the validation testing produce a number $V=0.95$, considered adequate. Finally, the results of the system testing contain an average maintainability index of 63.16 (green) and navigation works to reach $100 \%$ when run.
\end{abstract}

Keywords: software, visual studio, MySQL, continuous development, laboratory management

18

Copyright (C) 2020 JEC | ISSN 2715-3029 (p) 2685-4880 (e)

Volume 2, Nomor 1, 2020 


\begin{abstract}
Abstrak
Penelitian ini bertujuan untuk mengembangkan perangkat berbentuk program (perangkat lunak) untuk komputer dengan model pengembangan jenis Unified Process (UP). Pengembangan ini memerlukan program Microsoft Visual Studio Enterprise 2019 (Visual Basic.Net) dengan MySQL Workbench 8.0 CE sebagai database. Setelah program dibuat, program ini dilakukan uji unit, integration, validation (alpha and beta testing) dan system testing. Berdasarkan hasil pengujian, program ini dinilai sangat layak. Pengujian unit dan integration mencapai tingkat keberhasilan 100\%. Hasil validation testing menunjukkan angka $\mathrm{V}=0,95$, dianggap memadai. Terakhir, hasil system testing menunjukkan rata-rata maintainability index sebesar 63,16 (daerah hijau) dan navigasi berfungsi mencapai $100 \%$ saat dijalankan.
\end{abstract}

Kata Kunci: perangkat lunak, visual studio, mysql, pengembangan berkelanjutan, manajemen laboratorium

\title{
Pendahuluan
}

Pengembangan yang berkelanjutan atau Sustainable Development sudah menjadi gerakan kesadaran dunia akan perilaku manusia di bidang kimia salah satunya. Sejak awal diperkenalkan Rio Earth Summit pada Juni tahun 1992 (Strange \& Bayley, 2008) kemudian pertamakalinya diperkenalkan rumusan tujuannya di New York pada tahun 2015 oleh UN (Sarkar, 2015; Barbier \& Burgess, 2017). Selanjutnya, gerakan ini mulai menjamur pada berbagai pertemuan di antaranya, Green Chemistry \& Commerce Council yang menyampaikan isu ekonomi di bidang kimia, International Chemicals Management (SAICM) dan International Conference on Chemicals Management (ICCM) (Hassan, et al, 2006). Isu mengenai pengembangan berkelanjutan ini menjadi perhatian khusus dari berbagai bidang ahli yang ada di dunia, termasuk pada bidang kimia.

Pengembangan yang berkelanjutan dalam mempertimbangkan dampak perilaku manusia memiliki tujuan dan indikator
(Ritayani, 2016). Sejumlah 6 dari 17 dari keseluruhan tujuan tersebut, atau disebut juga Sustainable Development Goals (SDGs) mengatur mengenai pembangunan lingkungan (BAPPENAS, 2017). Salah satunya, terdapat tujuan yang memuat pengolahan limbah (Ministry Of National Development Planning, 2017). Bahkan, diadakan regulasi untuk menekan pengadaan manajemen limbah (Burns, 2013; Kementerian Perencanaan dan Pembangunan Nasional, 2017). Oleh sebab itu, salah satu langkah dalam menangani masalah lingkungan yaitu dengan memanajemen limbah dengan baik.

Pengelolaan limbah telah dimasukkan indikator dalam tujuan pengembangan berkelanjutan. Dalam hal ini, laboratorium kimia menjadi salah satu instansi yang berperan dalam pelaporan data yang bertanggung jawab sebab target capaian SDGs (Tujuan 12.4.2.a) tiap tahunnya meningkat (BAPPENAS, 2017). Informasi yang sistematis terkait data limbah 
diperlukan untuk tercapainya target data informasi limbah.

Berdasarkan observasi awal, inventaris alat dan bahan kimia yang ada di Laboratorium Kimia UIN Walisongo masih dicatat dengan buku catatan (Fuadah, wawancara 19 Februari 2019). Perjalanannya, dalam penggunaan masih ditemukan kekurangan dalam hal keamanan dan efisiensi (Mughis, wawancara 18 Februari 2019; Yuniar, wawancara 19 Februari). Tentunya, hal ini bertolak belakang dengan gerakan office paperless dalam upaya efisiensi bidang teknologi pada tahun 1970an (Strange \& Bayley, 2008). Model Pencatatan seperti ini juga masih belum memenuhi prinsip pendekatan STSE (Science, Technology, Society \& Environment) (Juntunen, 2015). Padahal salah satu kompetensi yang dimiliki laboratorium salah satunya yakni mengenai sistem informasi, seperti yang dimuat pada standar ISO.

Prasarana yang dapat menyediakan sumber pengolahan informasi mengenai inventarisasi alat dan bahan laboratorium adalah perangkat lunak sistem manajemen. Penelitian yang mengembangkan prasaran terkait hal ini pernah dikembangkan sebelumnya, Suryaningsih (2017) membuat pengelolaan Laboratorium fisika UIN Walisongo, via database MySQL berbahasa PHP (Hypertext Preprocessor), begitu juga dengan Maryani (2019) membuat web untuk laboratorium kimia UIN Walisongo dengan Apache. Namun, pada sistem informasi semacam ini memiliki kekurangan pada keamanan siber, ditambah belum ada data khusus mengenai data limbah, SOP (Standard Operational Procedure) dan SDS (Safety Data Sheet). Oleh sebab itu, berdasarkan permasalahan yang telah ditelusuri tersebut, peneliti bermaksud untuk membangun program sistem manajemen laboratorium kimia uin walisongo menggunakan Microsoft Visual Studio Community 2019 berbasis pengembangan berkelanjutan (Hidayatullah, 2012).

\section{Metode Penelitian}

Jenis penelitian yang digunakan adalah Penelitian dan Pengembangan. Pada penelitian ini diamksudkan untuk membuat program komputer yang didasari atas kebutuhan pada laboratorium kimia. Subjek penelitian pengembangan ini di antaranya Ketua Pranata Laboratorium dan Asisten Laboratorium. Laboratorium. Tempat diadakan penelitian yaitu di Laboratorium Kimia UIN Walisongo Semarang, kampus 2 yang berada di lantai 1 dan lantai 2.

Jenis model pengembangan yang digunakan adalah Unified Process (UP). UP memiliki beberapa fase dan tahapan, yaitu fase Inception, elaboration, construction, transition dan production dengan tahapan communication, planning, modeling, construction dan deployment bersifat siklus. Adapun penjabaran langkahnya sebagai berikut:

\section{Fase Inception}

Pada fase ini Peneliti melakukan observasi awal terhadap tempat serta mengumpulkan data melalui wawancara kepada narasumber (asisten laboratorium). Peneliti pada tahap ini dalam konteks proses UP, dilakukan proses komunikasi dengan pelanggan dari produk.

\section{Fase Elaboration}

Setelah mendapatkan hasil analisis kebutuhan, peneliti merancang use case. Use case ini digunakan sebagai protokol dalam pembuatan produk.

\section{Fase Construction}

Pada fase ini dilakukan penulisan kode (coding) pada tampilan antarmuka yang sudah didesain sebelumnya. Sehingga, tampilan antarmuka dapat menjalankan tugasnya sesuai dengan use case. Pada fase ini juga dilakukan pengujian unit testing. 


\section{Fase Transition}

Pengujian pada produk dilakukan sistematis. Setelah melakukan unit testing, dilakukan beta testing. Peneliti memberikan kuesioner berupa SUPR-Q kepada calon pengguna yang representatif terhadap produk yang akan dirilis.

\section{Fase Production}

Pada fase production, produk yang sudah dinyatakan valid dapat dirilis dan dimonitor. Proses UP dapat dilaksanakan siklus secara berulang apabila fase ini sudah dilewati. Hal ini bertujuan untuk pengembangan keberlanjutan produk, apabila ditemui keluhan untuk perbaikan.

Analisis data dilakukan setelah mendapatkan data hasil dari beberapa pengujian, dari mulai unit testing hingga system testing. Adapun analisisnya sebagai berikut:

\section{Unit Testing}

Sumber kode (source code) yang telah ditulis pada fase construction dapat dianalisis kualitasnya menggunakan unit testing. Analisis ini dapat diikuti dengan koreksi terhadap error yang terjadi pada kode, dengan mengulang fase construction. Sebagai indikator berhasil atau tidaknya sebuah alur, maka dapat ditentukan menggunakan digram alir input dan output. Adapun langkah penentuannya, kita harus menghitung $V(G)$ atau jalur independen (independent path) terlebih dahulu menggunakan rumus Pressman (2010). Rumus jumlah jalur independen yang harus diuji.

$$
\mathrm{V}(\mathrm{G})=\mathrm{E}-\mathrm{N}+2
$$

\section{Integration Testing}

Integration testing menghasilkan analisis

terhadap keberhasilan skenario yang diturunkan dari flowchart. Pembuatan skenario ini harus berkesuaian dengan rencana pada use case. Skenario ini diharapkan berhasil pada pengujian ini, kemudian agar dapat dilakukan pengujian selanjutnya yakni validation testing.

\section{Validation Testing}

Validation testing didasarkan dari penilaian yang dilakukan oleh pakar (alpha testing) dan calon pengguna (beta testing). Pemberian instrumen penilaian pada alpha testing butir penilaian disesuaikan oleh bidang masing-masing pakar, sedangkan pada beta testing diseragamkan.

Validitas alpha testing ditentukan menggunakan nilai validitas, atau $\mathrm{V}$ Aiken (1980) dengan alat ukur tabel Aiken (1985). Rumusnya, sebagai berikut:

$$
\begin{aligned}
& \mathrm{V}=\sum \mathrm{s} /[\mathrm{n}(\mathrm{c}-1)] \\
& \text { Keterangan: } \\
& \mathrm{s}=\mathrm{r}-\mathrm{lo} \\
& \text { lo= kategori rating terendah } \\
& \mathrm{c}=\text { kategori rating } \\
& \mathrm{r}=\text { angka penilai }
\end{aligned}
$$

\section{System Testing}

Analisis untuk menganalis kinerja sistem dari program yang sudah dibuat. Pengujiannya menggunakan beberapa program di antaranya, Code Metric, Performance Profiler, Rapise 6.1.16.09.

\section{Hasil Penelitian dan Pembahasan}

\section{Implementasi Desain Antarmuka}

Tampilan antarmuka terdiri atas desain tampilan form, tombol-tombol, icon. Dalam pembuatan desain tampilan form, tombol dan icon digunakan program Corel Draw X7 dengan hasil style gambar vector. Sebagian tombol juga ada yang dibuat menggunakan produk desain UI yang didapat dari komponen framework Bunifu. 


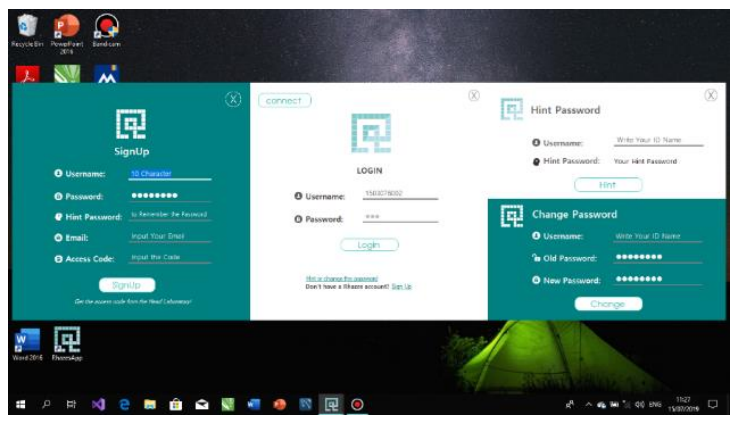

Gambar 1. Tampilan Antarmuka Login, Signup dan Change And Hint Password

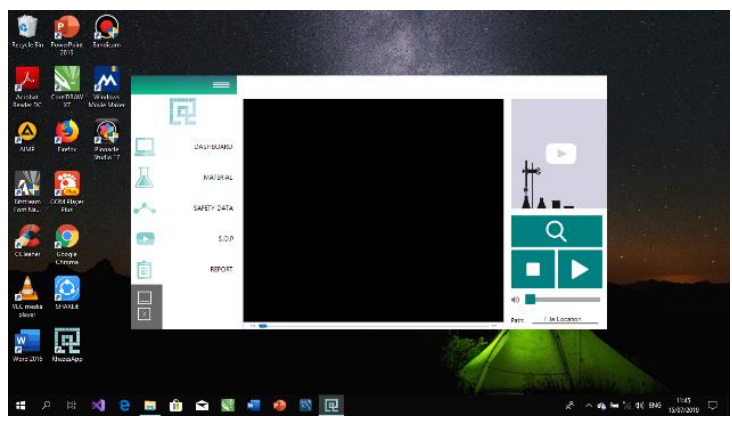

Gambar 2. Tampilan Antarmuka Form Utama

\section{Implementasi Database}

Database yang telah dibuat didasari atas analisis kebutuhan terkait apa saja informasi yang dibutuhkan. Database ini dapat dioperasikan dengan instruksi SQL melalui framework MySQL versi Workbench 8.0 CE yang telah dienkripsi. Pengoperasiannya di antaranya, insert, select, update, delete. Tabel yang telah dibuat ini berfungsi untuk penyimpnan database pengolahan alat dan bahan (Menu Dashboard), Perekaman Penyimpanan (Menu Material) dan rekap hasil data beserta pengolahan limbah (Menu Report) (Entreprise, 2018).

\begin{tabular}{|c|c|c|}
\hline Lis & Table Name: & material \\
\hline Column Name & & Datatype \\
\hline$?$ idmaterial & & VARCHAR (45) \\
\hline name_mat & & VARCHAR(45) \\
\hline othername_mat & & VARCHAR(45) \\
\hline code_mat & & VARCHAR(45) \\
\hline storage_mat & & VARCHAR(45) \\
\hline quantity_mat & & INT(11) \\
\hline unit_mat & & VARCHAR(45) \\
\hline available_mat & & DATE \\
\hline expired_mat & & DATE \\
\hline$\checkmark$ remnant_mat & & INT(11) \\
\hline price & & INT(11) \\
\hline
\end{tabular}

Gambar 3. Kolom Tabel Beserta Tipe Datanya pada Tabel Menu Material

\section{Implementasi Kode}

Pengimplementasian kode dilakukan di editor kode untuk memberikan sintaksis pada tampilan antarmuka, sehingga sesuai dengan kinerja pada rancangan use case dan flowchart. Kode hasil dari kegiatan ini secara berkala juga dilakukan pengecekan error dengan cara debugging.

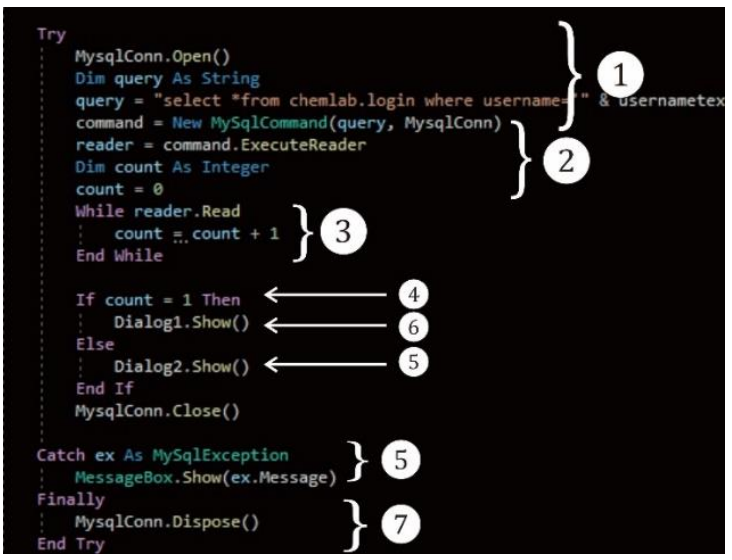

Gambar 4. Tampilan Editor Kode Form Login

Pada sintaksis ini digunakan sintaksis jenis perulangan dan percabangan. Pada Gambar 4, terdapat angka 1 sampai 7 yang memiliki relasi dengan flowgraph pada form Login yang terdapat pada Gambar 5. 


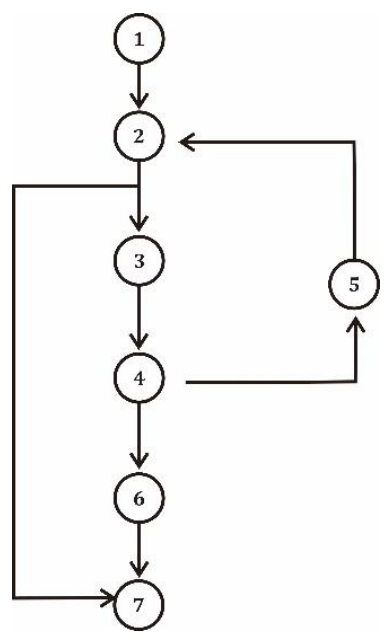

Gambar 5. Flowgraph dari form Login

\section{Hasil Pengujian}

\section{Hasil Unit Testing}

Pengujian unit testing berdasarkan penelusuran menggunakan rumus $V(G)$ dari flowgraph, ditemukan jumlah jalur form Login, SignUp, Hint and Change Password, Dashboard, Material, SOP dan Report berturut-turut yaitu 3, $3,6,10,16,2,2$ dan 18 dengan keseluruhan yakni 60 jalur. Keberhasilan pada unit testing sebesar $100 \%$, artinya program berjalan sesuai flowgraph yang telah dimodelkan.

\section{Hasil Integration Testing}

Skenario pada use case yang telah dimodelkan sebanyak 105 skenario dengan persentase $100 \%$ sesuai dengan skenario. Hal ini menandakan bahwa tampilan antarmuka (UI) selaras dengan kegunaannya sebagai User Experience (UX), sehingga siap untuk diuji pada tahap selanjutnya oleh brainware.

\section{Hasil Validation Testing}

Nilai yang didapatkan pada validasi alpha menghasilkan tiga nilai. Pemberi nilai pada aspek manajemen laboratorium ditandai dengan $r_{1}$, pemberi nilai aspek GUI ditandai dengan $r_{2}$, kemudian pemberi nilai pada aspek Rekayasa Perangkat Lunak (RPL) ditandai dengan $r_{3}$. Hasil ketiganya, masing-masing $r_{1}=$ 4,6, $r_{2}=4,75$ dan $r_{3}=5$. Sehingga, didapatkan nilai $s$ (r-lo) berturut-turut yaitu $s_{1}=3,6, s_{2}=$ $3,75, s_{3}=4$. Kemudian, digunakan rumus $V$ Aiken, peneliti mendapatkan hasil $V=0,95$. Hasil ini dinilai menurut tabel koefisien Aiken, dinyatakan bahwa produk ini memadai (mendekati koefisien=1).

Beta testing dilakukan oleh responden yang berjumlah tiga yang merupakan asisten laboratorium kimia, ditandai dengan $r_{1}, r_{2}$ dan $r_{3}$. Rata-rata nilai berdasarkan angket SUPR-Q untuk $r_{1}, r_{2}$ dan $r_{3}$ berturut-turut adalah 4,91, 4,91 dan 5,00. Hasil instrumen ini menentukan bahwa produk yang diuji coba dapat diterima oleh responden yang representatif dengan calon pengguna.

\section{Hasil System Testing}

System testing menghasilkan indeks dan grafik yang berasal dari uji menggunakan tester berupa software. Indeks dan grafik tersebut di antaranya yakni maintainability index (menggunakan code metric visual studio), grafik performance profile, dan tabel Rapise.

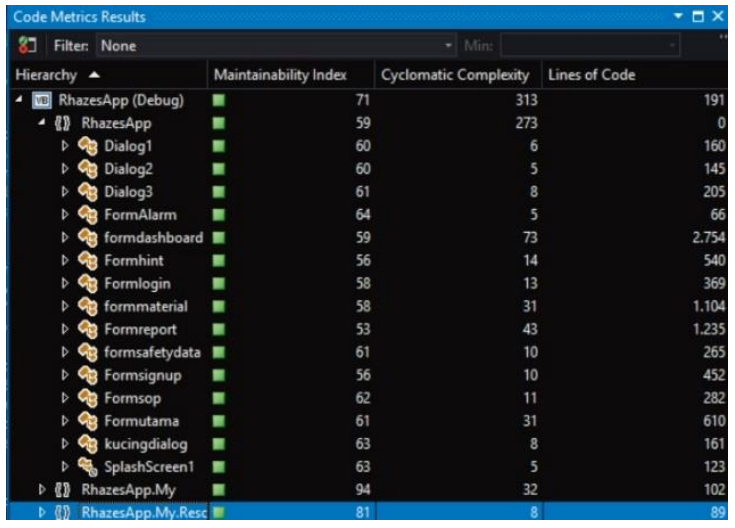

Gambar 6. Hasil Uji Code Metric

Copyright (C) 2020 JEC | ISSN 2715-3029 (p) 2685-4880 (e) Volume 2, Nomor 1, 2020 
Maintainability index menggunakan code metric pada visual studio mencapai ratarata 63,16. termasuk ke dalam kategori berwarna hijau (baik) menurut skala microsoft, dengan rentang 20 sampai 100 . Jadi, program ini dinilai dapat dengan mudah diperbaiki atau dimodifikasi.

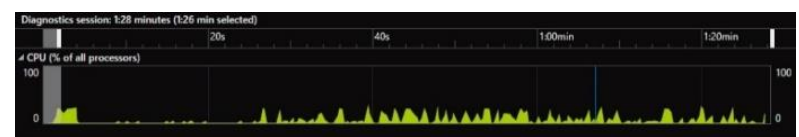

Gambar 7. Grafik Performance Profiler

Performance profile ditelusuri melalui grafik kinerja program menggunakan salah satu profiler pada visual studio. Hasilnya berupa grafik yang dapat diperinci kinerjanya dalam bentuk tabel CPU Total dan Self-CPU. Peneliti mendapatkan hasil rincian kinerja dari mulai awal form hingga akhir memiliki nilai rata-rata CPU total sebesar $\sim 0,03 \%$, sedangkan dari tinjauan self-CPU rata-rata sebesar $\sim 0,01 \%$.

Hasil pengujian menggunakan Rapise menghasilkan rekaman berbentuk tabel yang menjelaskan alur kinerja navigasi pada program. Kolom pada tabel yang terdiri dari object dan action yang dapat diteliti. Hasil menunjukkan bahwa seluruh tombol navigasi pada program Rhazes berjalan dengan baik (sesuai) dan tidak ada yang error.

\section{Simpulan}

Pengembangan program sistem manajemen laboratorium kimia UIN Walisongo berbasis pengembangan berkelanjutan telah dilakukan dengan model pengembangan Unified Process (UP) yang memiliki fase Inception, elaboration, construction, transition dan production yang berproses secara bersiklus. Proses pengembangan produk ini dibantu dengan dua program utama yaitu Microsoft Visual Studio Community 2019 (bahasa Visual Basic.Net) dan MySQL Workbench 8.0 CE sebagai database. Sehingga, produk ini

24

Copyright (C) 2020 JEC | ISSN 2715-3029 (p) 2685-4880 (e)

Volume 2, Nomor 1, 2020 direalisasi dan dinamakan Rhazes. Produk ini kemudian diuji dan dinyatakan valid berdasarkan unit testing, integration testing, validation testing dan System Testing.

\section{Daftar Pustaka}

Aiken, L. R. (1980). Content validity and Reliability of Single Items or Questionnaires. Educational and Psychological Measurement. 40(4): 955-959.

Aiken, L. R. (1985). Three Coefficients for Analyzing the Reliability and Validity of Ratings. Educational and Psychological Measurement. 45(1): 131-142.

Badan Perencanaan Pembangunan Nasional (BAPPENAS). (2017). Metadata Indikator: Tujuan Pembangunan Berkelanjutan (TPB)/Sustainable Development Goals (SDGs) Indonesia. Jakarta: Sekretariat SDGs

. Pedoman Penyusunan Rencana Aksi Tujuan Pembangunan Berkelanjutan (TPB)/ Sustainable Development Goals (SDGs). Jakarta: Kementerian Perencanaan Pembangunan

Barbier, E. B., \& Burgess, J. C. (2017). The Sustainable Development Goals and the systems approach to sustainability. Economics: The Open-Access, OpenAssessment E-Journal. 11(3): 1-23.

Burns, T.R. (2013). Sustainable Development. Sociopedia.isa. DOI: $10.1177 / 205684601392$

Entreprise, J. (2018). Step by Step MS SQL Server. Jakarta: Elex Media Komputindo.

Hassan, A. B., Abolarin, M. S., \& Jimoh, O. H. (2006). The application of Visual Basic Computer Programming Language To Simulate Numerical Iterations. Leonardo Journal of Sciences. 9: 125-136.

Hidayatullah, P. (2012). Visual Basic .NET Membuat Aplikasi Database Dan Program Kreatif. Bandung:Informatika. 
Juntunen, M. (2015). Holistic and Inquiry-Based Education for Sustainable Development in Chemistry. Disertasi tidak dipublikaiskan. University of Helsinki, Faculty of Science, Department of Chemistry.

Maryani, U.R. (2019). Pengembangan Sistem Pengelolaan Administrasi Laboratorium Berbasis Web di Laboratorium Kimia UIN Walisongo. Skripsi tidak dipublikasikan. Semarang: UIN Walisongo Semarang

Ministry Of National Development Planning. (2017). Voluntary National Review (Vnr): Eradicating Poverty And Promoting Prosperityin A Changing World. National Development Planning Agency

Pressman, R. S. (2010). Software Engineering: A Practitioner's Approach. McGraw-Hill: Palgrave macmillan

Ritayani. (2016). Pengantar Algoritma dan Pemrograman. Jurnal TIKA. 1(2): 72-79

Sarkar, D.D. (2015). Visual Studio Professional: A Benchmark in Bioinformatics. IJCST. 6(2): 15-18.

Strange, T. \& Bayley, A. (2008). Sustainable Development: Linking Economy, Society, Environment. OECD

Suryaningsih, S. (2017). Pengembangan Sistem Pengelolaan Administrasi Laboratorium Fisika UIN Walisongo Semarang Berbasis Web. Skripsi tidak dipublikasikan. Semarang: UIN Walisongo

WECF. (2017). Beyond 2020: Green Chemistry and Sustainable Chemistry (2017) 